\title{
Up-dating: Ratings of perceived dating success are better online than offline
}

\author{
Chris Fullwood* \& Alison Attrill \\ Institute of Psychology, University of Wolverhampton, UK
}

*Corresponding author

Dr Chris Fullwood

Institute of Psychology

Faculty of Education, Health and Wellbeing

University of Wolverhampton

West Midlands

WV1 1LY

UK

E-mail: c.fullwood@wlv.ac.uk

Phone: +441902323531

\section{Abstract}

The primary aims of this study were to test whether perceived dating success would differ between offline and online zero-acquaintance dating contexts, and to investigate the role that self-esteem might play in these evaluations. Participants were presented with the same photos of targets in either an offline or online dating scenario and rated their chances of dating success along with their perceptions of how attractive they thought the target would consider them. Higher self-esteem individuals believed they would be rated as more attractive. There was an overall perception that, irrespective of self-esteem level, meeting online would lead to better chances of dating success. These findings are considered in relation to an increased ability to more precisely manage impressions and develop an image of the self which would be evaluated more positively online. 


\section{Introduction}

Looking for a partner online is becoming more common and is often the preferred method of narrowing down a vast pool of connections to single out potential dates and mates ${ }^{1}$. Evidence suggests that online encounters lead to higher levels of marital satisfaction and are less likely to end in divorce than comparative relationships formed entirely offline ${ }^{2}$. Whilst positive reports of online dating success might motivate people to seek a new partner online, it currently remains unknown as to whether individuals do really believe that they will have more dating success online than offline. Further, the role of one's perceived attractiveness to others in online date selections remains largely unexplored.

In traditional offline research, various hypotheses have been tested to ascertain how one's own self-perceptions determine mate selection choices. From the 'similarities attract' to the 'opposites attract' hypotheses', the attitudes we have about ourselves are implicitly assumed to determine both date and partner choices offline, with levels of self-esteem influencing those self-perceptions ${ }^{4}$. Yet, a search of the extant literature reveals that very little work has assessed how one's own self-perceptions not only influence how people process information about others, but may also skew their perceived likelihood of dating success when selectively contacting potential daters online. One would not necessarily expect online behaviour to be analogous with offline behaviour in this respect. Indeed, many theorists argue that we have greater control over self-presentation in cyberspace, with the potential to present a more idealised version of the self, for example through carefully selecting photographs to display ourselves in the most attractive light or accentuating the positives in self-descriptions ${ }^{5,6,7}$. This notion is in line with that postulated 
by hyperpersonal theory, according to which the idiosyncratic features of cyberspace and the use of asnynchronous online communications enable people to edit and re-edit to perfection their most optimal version of self to present online ${ }^{8}$. Work that has considered how individual characteristics impact on online dating behaviour have tended to focus on the big five personality traits ${ }^{9,10,11}$ and social anxiety and loneliness ${ }^{9,12,13}$, with self-esteem ${ }^{9}$ having received far less attention. The current work explores whether self-esteem and the act of contacting a potential romantic partner online impact on perceived chances of dating success, with the most obvious starting point for the work being the use of online dating websites.

The very nature of online dating websites renders them akin to a catalogue of photographs to be flicked through until a suitable candidate catches one's eye. Indeed, profile pictures can be the single most important determinant of a dater being contacted and influence perceptions of whole profile attractiveness ${ }^{15,16}$. It is therefore unsurprising that daters want to present themselves in the best possible light. Many researchers have promoted the notion that online daters create idealised images of the self with the intentional deception of appearing more attractive online than offline ${ }^{16,7}$. Recent research purports however that online daters may be less inclined to intentionally deceive others when there is an anticipation of a future meeting ${ }^{17}$. Citing Goffman's ${ }^{18}$ notion of life being nothing more than a stage on which we all perform through manipulated self-presentation, and Bozeman and Kacmar's self-regulation model ${ }^{19}$, Zytko et al. ${ }^{17}$ suggest that whilst online daters try to influence the way in which they are perceived by other daters, they nonetheless strive to provide a truthful representation of self. Online daters may thus create profiles as a means to fulfil their goal of eventually meeting another dater offline. This is in line with the notion 
that people portray their self online in a goal-directed manner to fulfil an array of human needs ${ }^{20}$, including the need for social belonging ${ }^{21}$ and to romantically connect with another ${ }^{8}$.

Van Dijck ${ }^{22}$ notes that Internet arenas are associated with social norms that constrain and influence how people present themselves and interact with others. Ascribing to these social norms on online dating websites to achieve the desired goal of transferring to an offline relationship might inadvertently substantiate the notion of misleading potential mates in online dating. In order to meet basic human needs, one needs to present the best self possible online. Therefore, online daters have to walk a fine line between presenting an attractive and idealised online self (i.e. to attract potential dates), but at the same time reflecting an authentic version of the self in expectation of seeking a serious romantic connection offline ${ }^{23}$. On a night out at a singles event people will no doubt spruce themselves up to look the most attractive they can to other singletons with the aim of meeting these human needs and desires. The online equivalent of this is to present the best image of self possible. With this in mind, the two online and offline events share similar characteristics, with self-promotion being key to achieving the desired goal. One motivating factor that influences how people present in such situations is self-esteem ${ }^{24}$.

Self-esteem is the overall evaluation that one has about one's personal value or selfworth $^{25}$. Despite self-esteem playing a crucial role in determining date and partner choices offline ${ }^{4}$, little in the way of work has considered its role in online dating, with its evaluation in relation to online behaviour often focusing on a positive correlation with social networking site use $\mathrm{e}^{9,26}$. People with high self-esteem are often more motivated, driven and 
direct than their low-esteem counterparts in working towards desired goals ${ }^{27}$. These individuals might thus be more invested in maintaining a positive self-promotion online, especially as they are also known to be more accepting of risk and self-presentation than lower self-esteem individuals ${ }^{28}$. When lower self-esteem individuals consider romantic relationships to be important, evidence suggests that they may be less likely to use online dating services and this may be because promoting themselves to numerous singles simultaneously would be uncomfortable for them. In this sense, adopting an avoidance strategy might be one way for them to protect their own self-worth ${ }^{28}$. Therefore, although there has been some speculation that lower self-esteem individuals might be able to achieve a more level playing field online because of the increased potential to present an idealised version of the self (e.g. through tailored self-descriptions) $)^{5,6,7,8,29,30}$, they do not necessarily avail themselves of these opportunities by joining online dating sites.

As in the offline world, physical attraction plays a large role in determining with whom people strike up communication in online dating. Photographs of more attractive targets are rated as more sociable, warm, sensitive and successful in life than less attractive targets $^{31}$. Conversely, positive descriptions accompanying target photographs lead to ratings of higher levels of attractiveness ${ }^{32}$. Decades of research have conceptualised the physical attractiveness stereotype which suggests that levels of physical attractiveness are positively associated with levels of positive inner qualities ${ }^{31}$. Thus, people who are rated as good looking are more likely to be perceived to have desirable personality traits and characteristics, based purely on their physical appearance. In a similar vein, evidence suggests that the physical attractiveness of an online dating profile photo provides the strongest predictor of the desirability of a profile ${ }^{33}$, and that online dating profiles which 
have attractive photos receive more positive judgements ${ }^{14}$. People rarely want to posit a negative image of self, and likely want to project as positive an impression of the self as they can. According to hyperpersonal communications theory ${ }^{8}$, people are more able to carefully craft such a positive self-image online than offline. Thus, they are more likely to put forward images that most reflect their positive view of themselves online. If, we consider ideas in conjunction with the physical attractiveness stereotype, which suggests that people associate heightened levels of positive traits and qualities to those deemed more physically attractive, it could be expected that the carefully crafted online images might make a person appear to have more positive features and this could, in turn, enhance their perceived likelihood of receiving a date.

The current study was designed to test whether perceptions of dating success would differ between on- and off-line scenarios, and the role that self-esteem might also play in these perceptions. In order to achieve the goal of finding a romantic other with whom one can share a sense of belonging, online daters will undoubtedly wish to portray themselves in a positive and attractive light. If they have higher levels of self-esteem, they should be more likely to portray a true rather than ideal image of self, with high self-esteem often being associated with higher levels of self-acceptance. This difference in self-perception between high and low self-esteem individuals may carry over to how daters expect others to rate their image online. Alternatively, those who are lower in self-esteem may perceive their chances of attracting a date online as better than their potential offline success, possibly due to the absence of social cues online and ability to construct, edit and reconstruct their self whilst online. Participants were shown images of female and male targets and asked to rate these based on their own sexual orientation. They reported their level of self-esteem as 
well as how they felt a number of target others would rate them (i.e. how attractive and dateable the targets would find them) in an online or offline dating situation. It was predicted that expected attractiveness ratings would depend on levels of self-esteem and whether these are online or offline targets. According to the physical attractiveness stereotype, participants should expect to be rated as more attractive online than offline, and to overestimate the likelihood of being asked out on a date online. Moreover, a significant interaction of levels of self-esteem and dating location (online versus offline) was also expected, with low self-esteem individuals considering themselves to be more advantaged online.

\section{METHOD}

\section{Participants:}

127 participants (93 female) aged $16-40$ years (Mean $=23.94, \mathrm{SD}=4.90$ ) were randomly allocated to an offline $(n=71)$ or online $(n=56)$ dating condition. 54 participants indicated that they were single, 50 were in a 'serious' relationship, 11 were married, 9 were engaged and 3 in an 'open' relationship. Given the male to female participant ratio, it was important to ensure that sex was not a confounding factor on the dependent measures. There was no significant difference between males and females on the two dependent variables measured in this study, namely perceived dating success, (Males: $M=4.78, S D=1.50$; Females: $\mathrm{M}=4.49, \mathrm{SD}=1.55) \mathrm{t}(125)=.93, \mathrm{p}=.35$ and attractiveness ratings (Males: $\mathrm{M}=$ 5.25, $S D=1.47 ;$ Females: $M=4.88, S D=1.67) t(125)=1.14, p=.26$. Participants were recruited via advertisements placed on social media websites and through the Institute of Psychology's participant pool at the University of Wolverhampton, UK. 


\section{Materials:}

An initial pool of 48 photographs ( 24 male and 24 female) of target daters was compiled through searches of royalty free image websites. This pool was piloted on a sample of 26 participants to narrow down the size of the image set. Participants were asked to rate each photo on a 10-point Likert scale on 2 dimensions: 1) how attractive they perceived the person in the photo to be, and 2) to what extent they thought that the photo could represent an image of a real online dater. Twelve photos were then selected to form the final set of targets which included 6 males and 6 females, representing a range of attractiveness levels and photos which were ranked most highly in terms of their authenticity. The Rosenberg self-esteem scale ${ }^{33}$ was used to measure self-esteem. The scale, which consists of 10 items that participants rate on a 4 point scale of 'strongly agree' to 'strongly disagree', has been reported to have good reliability (Cronbach's alpha $=0.77)^{34}$.

\section{Procedure:}

Participants were presented with an information page describing the study and consent to participate was given through clicking a button onscreen. Participants first completed the Rosenberg Self-esteem scale ${ }^{34}$ before being exposed to photos of either the male or female targets. Participants in each condition (offline or online) were shown the same set of targets; however they were provided with a different set of opening instructions. Those who were assigned to the 'offline' condition were asked to imagine that the individuals in the photos were people that they had encountered whilst on a night out. Those in the 'online' condition were asked to imagine that they had joined a dating website and that the people in the photos were individuals whose profiles they were perusing in search of date. In both conditions participants were also asked to imagine that they were single and looking for 
love. They were then asked to rate each of the targets relevant to their own sexual orientation on a 10-point Likert scale for 2 questions: attractiveness (how attractive they considered the person in the photo would rate them) and dating success (how likely the person in the photo would be to go on a date with them if the participant contacted/approached them).

\section{RESULTS}

A median split divided participants into high $(n=51)$ and low $(n=76)$ self-esteem groups, having already been randomly assigned to either the online or offline dating condition. Means and standard deviations for all groups are shown in Table 1. Scores for the participants' rating of attractiveness and dating success for their 6 dating targets were averaged to provide a mean score for each dependent variable.

Table 1: mean scores (standard deviations in brackets) for dating success and attractiveness, as a function of location and selfesteem.

\begin{tabular}{cccc}
\hline & & Dating & \\
& & Success & Attractiveness \\
\hline \multirow{2}{*}{ Location } & Offline $(n=71)$ & $4.24(1.42)$ & $4.82(1.61)$ \\
& Online $(n=56)$ & $4.97(1.59)$ & $5.17(1.63)$ \\
Self- & Low $(n=76)$ & $4.40(1.37)$ & $4.66(1.55)$ \\
esteem & High $(n=51)$ & $4.81(1.74)$ & $5.44(1.62)$ \\
\hline
\end{tabular}

Participants' levels of self-esteem were positively correlated with their expectation of how the pictured others would rate their physical appearance $(r=.41, p<.001)$.

A two-way between groups multivariate analysis of variance assessed the effect of dating location (offline vs. online) and self-esteem (high vs. low) on levels of perceived success and 
estimated ratings of participant attractiveness by the pictured dating targets. Preliminary assumption testing checked for normality, linearity, univariate and multivariate outliers, homogeneity of variance-covariance matrices, and multicollinearity, revealing no serious violations. There was a significant difference of dating location on both success and attractiveness $(F(2,122)=5.35, p<.01$, Wilks' Lambda $=.92$, partial eta squared $=.08)$. Inspection of the between-subjects effects revealed that the factor of dating location affected levels of perceived success $(F(1,123)=7.31, p<.01)$, but not levels of attractiveness $(F(1,123)=1.49, p=.223$, using a Bonferroni corrected alpha level of .025). People thus thought that dating online $(M=4.97, S D=1.59)$ would lead to more success than dating offline $(M=4.24, S D=1.42)$. There was also a significant effect of self-esteem on both outcome factors $(F(2,122)=4.09, p<.05$, partial eta squared $=.06$, Wilks' Lambda $=.94)$. However, the interaction of dating location $\mathrm{x}$ self-esteem failed to reach significance $(F(2$, $122)=.61, p=.55$, partial eta squared $=.01$, Wilks' Lambda $=.99)$. The tests of betweensubjects effects revealed self-esteem to affect levels of the attractiveness factor $(F(1,123)=$ $7.21, p<.01)$, but not levels of perceived success $(F(1,123)=2.81, p=.09$ using a Bonferroni corrected alpha level of .025). Participants in the high self-esteem condition $(M=5.44, S D=$ 1.62) thought that the pictured targets would rate them as better looking than did those in the low self-esteem condition $(M=4.66, S D=1.55)$, but there was no difference in these groups between online and offline expectations of dating success.

\section{Discussion}

Findings demonstrate that self-esteem influences how one perceives that others will judge them in potential dating situations, with higher self-esteem individuals expecting targets to rate them as more attractive irrespective of dating location. This is unsurprising given that 
self-esteem is a form of affective-evaluative self-assessment, tied up with perceptions relating to one's own abilities and identity. It stands to reason that those who place more value on their own self-worth will likely consider themselves more capable of attracting the attention of potential mates ${ }^{4}$. Although we expected an interaction between self-esteem and dating location on perceptions of dating success, findings suggest that regardless of one's self-esteem, individuals may generally overestimate their chances of success in online dating comparative to an offline equivalent context. This finding is in support of both the poor-get-richer and rich-get-richer hypotheses ${ }^{35}$. In other words, irrespective of whether one's self-evaluations are more positive or negative, the increased potential for flexible impression management online, and the presentation of idealised selves, may foster the perception of being capable of achieving a more favourable outcome. This might be, for example, because there is a perception that a more attractive image of self can be conveyed via dating profiles. This might be achieved, for instance, by selectively uploading the most desirable photographs or accentuating the positives in both self-descriptions and responses to other daters ${ }^{5,6,7,29,30}$. In this regard, Goffman's ${ }^{18}$ dramaturgical analogy of impression management represents a useful framework for interpreting these findings, with the online dater assuming the most desirable mask to win favour with fellow daters.

An alternative explanation could lie in the manner in which the targets themselves were perceived in their respective conditions. For example, it has been suggested that online daters are more likely to be perceived as desperate or lonely ${ }^{36}$. Given the growing acceptability and popularity of online dating ${ }^{1}$ we consider this explanation unlikely. The idea that perceptions of success may be artificially inflated in the online dating arena has a number of potential ramifications which should be considered in future research. For 
example, might this culminate in more unrealistic expectations for those who choose to pursue love online over more traditional methods and increase one's sense of entitlement? In addition, might this also impact one's chances of actual success as well as the likelihood of being satisfied with dates accrued from these sites and the potential to return to look for love again in the future?

Although the findings from this study provide a useful insight into factors which may aid our current understanding of online dating preferences and behaviours, there are a number of limitations which should be considered for future research. A number of potential factors which may have impacted on participant perceptions of dating success (in both on- and offline contexts) were not considered in this study and further research may wish to explore these. For example, we did not measure actual previous online dating experience. People who have tried online dating but had limited success for instance may temper their expectations during future interactions. Pre-existing attitudes to online dating may also impact on perceptions of prospective success. Indeed, findings suggest that people who know others who have used online dating are more likely to try it themselves and hold positive attitudes about it $^{37}$. It is also worth noting that the current data stem from selfreport measures, and in some cases, assumptions may have been made that participants inferred the same meaning of terminology as the researchers. For example, the use of the term attractiveness was implied to indicate physical attractiveness in this instance, but some participants may have inferred social or economic attractiveness. Future research should not only validate the findings using observational and behavioural measures but should also explore more how attractiveness is judged when considering online presentations. Nonetheless, a valuable contribution to the extant literature is made 
through the current findings, not least the introduction of a neglected factor of entitlement in online dating, in the form of expectations about who one would or would not potentially be able to realistically date. The current findings of a link to entitlement and dating success to levels of self-esteem also offer an exciting new avenue of research to understanding factors related to online dating. They lay foundations to build on wider research implications, such as the exploration of how individuals benefit from a combination of held stereotypes and asynchronous communication to engage in goal-directed manipulation of the self online, whether that goal be to find a life partner or engage in nefarious or criminal activity. Who people expect to be able to date online will ultimately influence who they let into their online lives.

\section{Author Disclosure Statement}

No competing financial interests exist.

\section{Acknowledgements}

We would like to thank Hollie Brown, Seema Chumber, Mark Hulme, Thomas James and Charlotte Redding for their help with recruitment and data collection.

\section{References}

1. Fox Hamilton N. (2016) Romantic relationships and online dating. In: Attrill A \& Fullwood C, eds. Applied Cyberpsychology: Practical applications of cyberpsychological theory and research. Palgrave MacMillan: UK, pp. 144-160.

2. Cacioppo JT, Cacioppo S, Gonzaga GC, Ogburn EL, VanderWeele TJ. Marital satisfaction and break-ups differ across on-line and off-line meeting venues. Proceedings of the National Academy of Sciences of the United States of America 2013; 10(25): 10135 - 10140.

3. Blackwell DL, Lichter DT. Mate selection among married and cohabiting couples. Journal of Family Issues 2000; 21: 275-302. 
4. Penke L, Todd PM, Lenton AP, Fasolo B. (2007) How self assessments can guide human mating decisions. In: Geher G \& Miller GF, eds. Mating intelligence: Sex, relationships, and the mind's reproductive system. Mahwah, NJ: Erlbaum, pp. 37-75.

5. Fullwood C. (2015) The role of personality in online self-presentation. In: Attrill A, ed. Cyberpsychology. Oxford University Press: Oxford, pp. 9-28.

6. Rosenberg J, Egbert N. Online impression management: Personality traits and concerns for secondary goals as predictors of self-presentation tactics on Facebook. Journal of Computer-Mediated Communication 2011; 17: 1-18.

7. Toma C, Hancock JT. What lies beneath: The linguistic traces of deception in online dating profiles. Journal of Communication 2012; 62(1): 78-97.

8. Walther JB. Selective self-presentation in computer-mediated communication: Hyperpersonal dimensions of technology, language, and cognition. Computers in Human Behavior 2007; 23: 2538-2557.

9. Blackhart GC, Fitzpatrick J, Williamson J. Dispositional factors predicting use of online dating sites and behaviors related to online dating. Computers in Human Behavior 2014; 33.

10. Guadagno RE, Okdie BM, Kruse S. Dating deception: Gender, online dating, and exaggerated self-presentation. Computers in Human Behavior 2012; 28: 642-647.

11. Hall JA, Park N, Song H, Cody MJ. Strategic misrepresentation in online dating: The effects of gender, self-monitoring, and personality traits. Journal of Social and Personal Relations 2010; 27: 117-135.

12. Stevens SB, Morris TL. College dating and social anxiety: Using the Internet as a means of connecting to others. CyberPsychology, Behavior and Social Networking 2007; 10: 680-688.

13. Valkenburg PM, Peter J. Who visits online dating sites? Exploring some characteristics of online daters. Cyberpsychology, Behavior and Social Networking. 2007; 10(6): 849-52.

14. Fiore AT, Shaw Taylor L, Mendelsohn GA, Hearst M. Assessing attractiveness in online dating profiles. Paper presented at the ACM Computer-Human Interaction conference 2008, Florence, Italy.

15. Hitsch GJ, Hortaçsu A, Ariely D. What makes you click? Mate preferences in online dating. Quantitative Marketing and Economics 2010; 8: 393-427.

16. Hancock JT, Toma C. Putting your best face forward: The accuracy of online dating photographs. Journal of Communication 2009; 59: 367-386.

17. Zytko D, Grandhi SA, Jones QG. Impression management through communication in online dating. In Proceedings of the CSCW 2014. New York: ACM, 277-280.

18. Goffman E. (1959) The presentation of self in everyday life. Garden City, NY: Anchor Books.

19. Bozeman DP, Kacmar KM. A cybernetic model of impression management processes in organizations. Organizational behavior and human decision processes 1997; 69(1): 9-30.

20. Attrill A. Sharing only parts of me: Selective categorical self-disclosure across Internet arenas. International Journal of Internet Science 2012; 7(1): 55-77.

21. Seidman G. Self-presentation and belonging on Facebook: How personality influences social media use and motivations. Personality and Individual Differences 2013; 54: 402-407.

22. Van Dijck J. (2013) The culture of connectivity: A critical history of social media. New York: Oxford University Press.

23. Ellison N, Heino R, Gibbs J. Managing impressions online: Self-presentation processes in the online dating environment. Journal of Computer-Mediated Communication 2006; 11: 415-441. 
24. Baumeister RF, Tice DM, Hutton DG. Self-presentational motivations and personality differences in self-esteem. Journal of Personality 1989; 57(3): 547-579.

25. Hewitt JP. (2009) Oxford Handbook of Positive Psychology. Oxford: Oxford University Press.

26. Forest A, Wood J. When social networking is not working: Individuals with low selfesteem recognize but do not reap the benefits of self-disclosure on Facebook. Psychological Science 2012; 23(3): 295-302.

27. Erez A, Judge TA. Relationship of core self-evaluations to goal setting, motivation, and performance. Journal of Applied Psychology 2001; 86: 1270-1279.

28. Kim M, Kwon KN, Lee M. Psychological characteristics of internet dating service users: the effect of self-esteem, involvement, and sociability on the use of internet dating services. CyberPsychology \& Behavior 2009; 12(4): 445-449

29. McKenna KYA, Green AS, Gleeson MJ. Relationship formation on the Internet: What's the big attraction? Journal of Social Issues 2002; 58: 9-32.

30. Walther JB, Parks M. (2002). Cues filtered out, cues filtered in. In: Knapp ML, Daly JA, eds. Handbook of interpersonal communication. Thousand Oaks, CA: Sage, pp. 529-563.

31. Dion K, Berscheid E, Walster E. What is beautiful is good. Journal of Personality and Social Psychology 1972; 24(3): 285-290.

32. Gross AE, Crofton C. What is good is beautiful. Sociometry 1977; 40(1); 85-90.

33. Fiore A, Taylor LS, Mendelsohn GA, Hearst M. Assessing attractiveness in online dating profiles. $\mathrm{CHI}$ '08 Proceedings of the SIGCHI Conference on Human Factors in Computing Systems 2008; 797-806.

34. Rosenberg M. (1965) Society and the adolescent self-image. Princeton, NJ: Princeton University Press.

35. Zywica J, Danowski J. The faces of Facebookers: Investigating social enhancement and social compensation hypotheses; predicting Facebook and offline popularity from sociability and self-esteem, and mapping the meanings of popularity with semantic networks. Journal of Computer Mediated Communication 2008; 14(1): 1-34.

36. Brym RJ, Lenton RL. Love online: A report on digital dating in Canada 2001. Retrieved October, 2016, from http://projects.chass.utoronto.ca/brym/loveonline.pdf

37. Hogan B, Li N, Dutton WH. A global shift in the social relationships of networked individuals: Meeting and dating online comes of age 2011. Oxford Internet Institute, University of Oxford. Retrieved February, 2017, from

http://www.oii.ox.ac.uk/research/projects/?id=47 